\title{
Representações de gênero no voleibol brasileiro: a imagem do teto de vidro
}

\author{
Sandra Bellas Romariz* \\ Sebastião Josué Votre ${ }^{* *}$ \\ Ludmila Mourão***
}

\begin{abstract}
Resumo: O objetivo deste artigo foi investigar as oportunidades e barreiras que técnicos(as) de voleibol de alto rendimento de equipes profissionais encontram na construção de sua carreira. Foram entrevistados quatro técnicos e cinco técnicas e seus discursos analisados através da Análise do Conteúdo. Os resultados mostram que para os técnicos ingressarem na carreira profissional é fundamental demonstrarem autonomia, experiência e o conhecimento técnico. E para as mulheres autonomia, experiência adquirida nas quadras e conhecimento técnico não garantem um convite para dirigirem equipes profissionais, confirmando a metáfora do "teto de vidro".
\end{abstract}

Palavras-chave: Voleibol. Identidade de Gênero. Mobilidade ocupacional.

\section{INTRODUÇÃo}

O esporte contemporâneo de rendimento no Brasil vê desaparecerem progressivamente as desigualdades de oportunidades relacionadas a gênero. Estão afastados os preconceitos associados à prática esportiva pelo sexo feminino, que até há pouco perduravam, centrados em capacidade física, contato, força e velocidade, a exemplo do futebol, do futebol de praia, das lutas, do beisebol, do

\footnotetext{
"Laboratório de Estudos de Educação Física, esporte e cultura. Faculdades Integradas Maria Thereza e Universidade Gama Filho. Rio de Janeiro, RJ, Brasil. E-mail: sbellas@ig.com.br

"Curso de pós graduação em Educação Física. Universidade Gama Filho. Rio de Janeiro, RJ, Brasil. E-mail: sebastianovotre@yahoo.com

"'Universidade Federal de Juiz de Fora. Juiz de Fora, MG Brasil. E-mail: ludmila.mourao@terra.com.br
} 
halterofilismo e do pólo aquático (MOURÃO, 2003). As representações biológicas do corpo, que afastavam as mulheres destes esportes ditos viris se viram enfraquecidas e não ancoram mais o entendimento de que esporte é coisa de homem. Hoje, esporte é prática para homens e mulheres em todas as suas modalidades.

É inegável que aconteceram progressos consideráveis em relação aos direitos das mulheres e à igualdade de gênero no Brasil. Muitas ações, em diferentes instâncias sociais, econômicas e políticas, desde a década de 1950, colaboraram com essas mudanças, alterando comportamentos e atitudes frente à prática feminina em diferentes domínios profissionais. A profissionalização do esporte é uma delas, que cedeu espaço a profissionais com melhor desempenho, independentemente do sexo.

Nas últimas décadas, também testemunhamos o crescimento da presença feminina em posições executivas nas empresas, na gerência de negócios e na política. No campo do trabalho, atividades consideradas antes de atuação masculina, por exigirem força física, neutralizaram o gênero, sobretudo pelos avanços da tecnologia. No esporte de alto rendimento a situação não foi diferente. Identificado com traços de guerreiro, representado por força, vigor, estratégia e determinação, esse tipo de esporte sempre se destinou mais aos homens do que às mulheres. Hoje, constata-se que a maioria das modalidades esportivas não provoca mais tensões de gênero e configura-se como um campo de possibilidades em que homens e mulheres podem manifestar seus desejos e interesses como praticantes e atletas.

Nos Estados Unidos da América, por exemplo, na década 1970, as alterações da Lei da Educação de 1972, (Title IX ${ }^{1}$ ), da Constituição norte-americana, determinaram que instituições esportivas, educacionais e empresariais oferecessem as mesmas oportunidades

\footnotetext{
${ }^{1}$ Title XI - Alterações da Lei da Educação 1972. Título 20 Seções 1681-1688. (a) proibição contra a discriminação: Nenhuma pessoa nos Estados Unidos pode, com base no sexo, ser excluída da participação, ter negado um benefício ou ser submetida a uma discriminação em qualquer programa de educação ou atividade que recebem assistência financeira federal [...]. Disponível em: <http://www.dol.gov/oasam/regs/statutes/titleix.htm>. Acesso em 5 abr 2009.
} 
para homens e mulheres que se envolvessem com o esporte. Esta normatização favoreceu e garantiu a participação e os movimentos e desejos femininos de atuação em qualquer instância do esporte no país. Já no Brasil as oportunidades para as mulheres no esporte não ocorreram da mesma forma. Seu acesso pleno ao esporte, em todas as manifestações, só foi garantido em dezembro de 1979, com a revogação do Decreto-Lei 3.199 de 1941 (Legislação Federal do Brasil), que proibia a prática de esportes como: lutas (judô, karatê, taekwondo entre outros), halterofilismo, futebol, futebol de praia, beisebol e pólo aquático. A deliberação 10/79 permitiu às mulheres sua prática em competições oficiais.

Para a atuação das mulheres como técnicas e gestoras muitos são os desafios a serem superados. Neste estudo, os desafios que nos provocam, na perspectiva da equidade de gênero, estão relacionados às atividades de administração e gestão do esporte. Questionamos por que encontramos poucas mulheres atuando no comando de times em clubes, federações e confederações, e mais, por que atuam em número tão reduzido como técnicas de seleções nacionais e de equipes esportivas de alto rendimento? E como se constitui este campo de forças da gestão esportiva nacional? Estudos recentes (MOUR ÃO, 2003; GOELLNER, 2009; ROMARIZ, 2010) apontam para uma baixa proporção de mulheres no comando das equipes de esporte de alto rendimento, configurando este espaço como de predomínio e domínio masculino. Alguns estudos nesta área temática, como os de Gomes (2008); Pfister e Radtke (2007); Mourão (1998, 2003) e Souza de Oliveira (2002), vêm acompanhando estas diferenças de oportunidades associadas a gênero no comando de equipes esportivas no Brasil, em desacordo com o que se passa em muitos países do mundo.

Na gestão do voleibol, tema desta pesquisa, a situação não é diferente, apesar de este ser um dos esportes coletivos mais praticados no Brasil pelas mulheres, desde o século XIX, observase que elas cresceram na prática, como atletas, mas não na gestão. São visíveis as desigualdades de gênero, com os homens em maioria 
absoluta, no comando de equipes de voleibol de rendimento, como na Superliga ${ }^{2}$, que é o campeonato de expressão máxima do esporte nacional. $\mathrm{O}$ mesmo se repete nas equipes nacionais e nas do Estado do Rio de Janeiro (LOCKS, 2009). Até hoje nenhuma técnica atuou no comando de equipes olímpicas femininas ${ }^{3}$ e/ou masculinas ${ }^{4}$ na história esportiva nacional.

O fato de não constatarmos a presença feminina na direção de equipes no voleibol de alto rendimento motivou-nos a investigar como técnicos e técnicas constroem suas carreiras levando em conta as oportunidades com que contam e criam e as dificuldades que encontram e superam, tendo como suporte analítico a categoria do sujeito reflexivo, proposta por Giddens (2002). Há consenso de que nos estudos da educação física brasileira carecemos de investigações sobre as relações de gênero na carreira de técnicos e técnicas no sistema esportivo de alto rendimento. Há consenso, também, de que as razões das desigualdades nesses cargos precisam ser diagnosticadas e interpretadas, para propiciar novas propostas de superação do quadro. A opção de incorporar a questão de gênero nas políticas esportivas é relativamente recente e relaciona-se às demandas por investigações na área, pelos movimentos organizados, bem como pelos organismos internacionais como o Comitê Olímpico Internacional.

\footnotetext{
${ }^{2}$ Superliga - Campeonato Nacional entre clubes do Brasil organizado pela Confederação Brasileira de Voleibol, anualmente, nos naipes femininos e masculinos.

${ }^{3}$ Técnicos da equipe feminina de voleibol nos JOs: De 1964 a 1976 - Não classificada; 1980 Enio de Figueiredo Silva e Josenildo da Rocha Carvalho 1984 - Enio de Figueiredo Silva e Jorge Barros de Araújo; 1988 - Jorge Barros de Araújo e Marco Aurélio Motta; 1992 - Wadson de Oliveira Lima e Antonio Rizola Neto; 1996 - Bernardo Rocha de Rezende e Ricardo Gomes Tabach; 2000 - Bernardo Rocha de Rezende e Ricardo Gomes Tabach; 2004 - José Roberto Lages Guimarães e Carlos Eduardo Bizzocchi / Paulo do Rego Barros Junior; 2008 - José Roberto Lages Guimarães. Disponível em: <htttp://www.volei.org.br>. Acesso em: 15 mar.09. ${ }^{4}$ Técnicos da equipe masculina de voleibol nos JOs: 1964 - Sabe Mehlinsky; 1968 - Paulo Emmanuel da Hora Matta; 1972 - Valderbi Romani; 1976 - Carlos Reinaldo Pereira Souto e Paulo Sevciuc; 1980 - Paulo Sevciuc e Paulo Roberto Laranjeiras Caldas; 1984 - Paulo Roberto de Freitas e José Carlos Brunoro; 1988 - Paulo Roberto de Freitas e Antonio Fernando Teixeira Leão; 1992 - José Roberto Lages Guimarães e Marcos Pinheiro Miranda; 1996 - José Roberto Lages Guimarães e Marcos Pinheiro Miranda; 2000 - Radamés Lattari Filho e Marcelo Dario Del Negro Gonçalves; 2004 - Bernardo Rocha de Rezende e Ricardo Gomes Tabach / José Francisco Filho; 2008 - Bernardo Rocha de Rezende. Disponível em: <htttp://www.volei.org.br>. Acesso em: 15 mar.09.
} 
Este estudo poderá contribuir para alicerçar a compreensão do empreendedorismo feminino no esporte de alto rendimento e, no campo prático, para preparar novas gerações de mulheres para os desafios que elas encontrarão no campo da gestão esportiva de alto rendimento.

\section{BASES TEÓRICAS DA PESQUISA}

Como método adotou-se o paradigma interpretativo e a abordagem qualitativa, segundo Thomas e Nelson (2007). Os sujeitos do estudo foram técnicos(as) de equipes de voleibol que atuaram em competições oficiais organizadas pelas Federações de voleibol do Rio de Janeiro e de São Paulo. A entrevista, do tipo semiestruturado, foi realizada com (05) técnicos e (04) técnicas. Tomamos como pressuposto que as respostas são dadas por sujeitos reflexivos, que continuamente interpretam o mundo em que vivem. As questões que orientaram o roteiro de entrevista tinham como temáticas: i) como mulheres e homens se iniciam e ascendem em cargos de comando de equipes de voleibol de rendimento; ii) o que as(os) motiva a almejar a carreira de técnica(o) de voleibol e quais barreiras encontraram em sua trajetória esportiva. As respostas foram analisadas e interpretadas tendo como referência a análise do conteúdo proposta por Bardin (2008) e as considerações de Moscovici (2009), para quem as representações sociais se apóiam na autoridade da tradição, sendo os preconceitos enunciados ao mesmo tempo na linguagem comum e na linguagem científica; e de Giddens (2002), com foco em sua postulação do sujeito reflexivo, que toma decisões com base nas interpretações que faz sobre o contexto imediato, e sobre como a transformação do tempo e do espaço, em conjunto com os mecanismos de desencaixe, afastam a vida social da influência de práticas e preceitos preestabelecidos.

Esta pesquisa foi aprovada pelo Comitê de Ética da Universidade Gama Filho, sob o número CAAE 0006.0.312.000-10 PARECER 020.2010. Os participantes do estudo assinaram o termo de consentimento livre e esclarecido (TCLE), exigido pelo comitê de ética e pesquisa em seres humanos. Onde foi detalhado todo o 
procedimento da pesquisa, juntamente com a manutenção e preservação da privacidade do participante. Garantimos às(aos) informantes o anonimato, identificando-as(os) com nomes fictícios.

\section{A metáfora do "teto de VIDRo" - decisões Metodológicas}

No cenário esportivo brasileiro, as manifestações políticas e econômicas associadas às reivindicações feministas, tomaram vulto na última década, no vácuo do usufruto dos direitos de cidadania. No voleibol brasileiro de alto rendimento, algumas atletas ensaiaram mudanças nas representações sobre a disponibilidade e competência feminina para a gestão técnica de equipes de alto rendimento, contrariando os valores culturais convencionais. A ex-atleta Isabel Barroso, atuou como primeira técnica de uma equipe feminina de voleibol profissional, na Superliga, (temporada 2000-2001). Entretanto, esse fato foi único, pois até os dias atuais nenhuma outra mulher chegou a dirigir equipes profissionais de voleibol no Brasil. Elas atuam em outras funções, como na avaliação técnica, equipe estatística, compondo a comissão técnica de equipes, entre outras funções. No cenário internacional, esta situação não é diferente. $\mathrm{Na}$ olimpíada de 2008, apenas Lang Ping atuou como técnica da equipe olímpica de Vôlei feminino dos Estados Unidos.

Diferentes estudos relacionados à gestão esportiva mostram a baixa participação de mulheres nos cargos de comando em diferentes países, nos quais a participação como atletas não mais encontra barreiras de gênero ${ }^{5}$. A distribuição está longe do equilíbrio quando nos reportamos aos cargos de liderança esportiva. De acordo com Gomes (2008), apenas 1,8\% dos profissionais que atuam no comando de confederações brasileiras são mulheres. A diferença entre os sexos se mantém no comando das federações esportivas nacionais,

\footnotetext{
${ }^{5} \mathrm{No}$ Brasil, apesar de o número de atletas de alto rendimento ser hoje praticamente o mesmo em ambos os sexos. Em 1964, na primeira participação do nosso voleibol em olimpíadas em Tóquio, o Brasil participou com uma mulher e 67 homens - a equipe feminina não conseguiu índice para vaga. Em 1980, em Moscou, participou com 15 mulheres e 94 homens. Foi a primeira participação da equipe feminina brasileira de voleibol. Em 2004,em Atenas, foram 122 mulheres e 125 homens, Em 2008, em Pequim, foram 133 mulheres e 144 homens.
} 
onde é de 6,5\% o percentual da participação das mulheres. O mesmo é observado no comando de equipes de alto rendimento onde poucas mulheres chegaram a atuar como técnicas de equipes olímpicas de esportes coletivos, Maria Helena Cardoso, ex-técnica da Seleção Brasileira de Basquete Feminina, é um exemplo desta exceção.

A situação não é muito diferente no cenário internacional. Na Alemanha, levantamento realizado em 2003 por Pfister e Radtke (2007) demonstra um crescimento relativo do número de mulheres em posições executivas honorárias de diversas organizações esportivas ${ }^{6}$. Mas, segundo as autoras, apesar desse aumento, elas ainda estão em minoria no quadro de posições executivas de clubes e nas Confederações de Esportes Regionais. Este fato é notório no maior clube esportivo da Alemanha, o Freiburger Kreis, onde as mulheres ocupam somente $19 \%$ das posições honorárias e executivas. Entre os 42 presidentes de clubes nacionais apenas duas são mulheres e entre 96 comissões da presidência de clubes apenas sete são femininas. Os números indicam que nos clubes da Alemanha as mulheres raramente são encontradas nas posições prestigiadas e de alto escalão. De acordo com Radtke (2006), elas estão engajadas de forma ativa dentro do sistema desportivo, nos esportes femininos e/ou nos infantis, áreas com salários menores e consideradas de menor prestígio, quando comparadas com a gestão e direção dos esportes de alto rendimento.

Uma interpretação para a representação desigual de mulheres em cargos de comando, segundo Soares (2010), é que elas não possuem controle emocional para suportar as pressões frequentes; não tomam decisões objetivas; são socialmente educadas para serem "protegidas", e desta forma, não adquirem a "agressividade" necessária para competir. Observa-se, nestes argumentos, a naturalização, que resulta em interpretar:

${ }^{6} \mathrm{Na}$ Confederação Alemã de Esportes o percentual de mulheres é de 40\%; na Federação de Esportes Acrobáticos, 73\%; na Federação Equestre, 70,4\%; na Federação de Ginástica, 70,2\%; na Federação de Dança Esportiva, 65,2\%; na Federação de Pentatlo Moderno, 57,5\%; na Federação de Voleibol, 52,3\%; e na Federação de Natação, 51,8\%. 
[...] "gênero", como uma categoria analítica, é um conceito importante para perceber os processos pelos quais, no interior de redes de poder, a diferença biológica é tomada para explicar desigualdades sociais gestando, assim, formas de inclusão e exclusão de sujeitos e grupos. (GOELLNER, 2008, p.5)

Para Soares (2010), estruturas institucionais tidas como inapropriadas às mulheres não propiciam o seu sucesso profissional; consequentemente impedem a chegada delas nas áreas de maior prestígio. Vários estudos buscam esclarecer as causas das desigualdades entre gêneros na área do trabalho esportivo. Dentre eles, Pfister e Radtke (2007) analisam as perspectivas e os problemas da participação de homens e mulheres na liderança esportiva, afastando-se das explicações monocausais para a distribuição assimétrica de oportunidades. As autoras afirmam que o papel do gênero na ocupação de um cargo pode ser descrito com o uso da metáfora do "teto de vidro" que, invisível, efetivamente impede ou ao menos dificulta as mulheres de chegar ao topo.

$\mathrm{Na}$ literatura econômica, os modelos teóricos como os de Becker, Arrow e Lazear \& Rosen discutem as causas do "teto de vidro". Dentre esses modelos, o de Becker (1957) e o de Arrow (1972) apontam a discriminação de gênero: Becker analisa a discriminação exercida pelo "empregador-discriminador", referindose ao empregador que prefere contratar um homem a uma mulher, mesmo que ambos tenham produtividade idêntica; o modelo de Arrow, chamado de "discriminação estatística", trabalha o pressuposto de que a produtividade das mulheres é menor do que a dos homens.

Já o modelo de Lazear e Rosen (1990) postula como causas para o fenômeno do "teto de vidro" as "diferenças comportamentais" entre homens e mulheres. A simples suposição de que as mulheres possuem tarefas maiores do que os homens em atividades domésticas (como, por exemplo, cuidar dos filhos pequenos) amplia a 
desvantagem da mulher no mercado, tendo como consequência a contratação de um maior número de homens pelas empresas ${ }^{7}$.

Visando à compreensão do cenário e das razões para as desigualdades de gênero no contexto do trabalho de técnica de equipes de voleibol de rendimento, nós nos guiamos pelas considerações de Moscovici (2009), para quem as representações sociais se apóiam na autoridade da tradição, sendo os preconceitos enunciados ao mesmo tempo na linguagem comum e na linguagem científica; e de Giddens (2002), com sua teoria do sujeito reflexivo, que organiza suas ações com base em decisões que toma após avaliar o efeito de cada decisão.

\section{ANÁLISE E DISCUSSAO DO DISCURSO DE GÊNERO NA QUADRA}

Considerando os resultados encontrados, podemos afirmar que as(os) entrevistadas(os) possuem maturidade, autonomia, experiência e competência técnica, características que compõem um perfil adequado para exercerem a função de técnica(o) de equipes de voleibol. Por outro lado, a análise dos dados evidencia desigualdade entre os dois grupos: (a) as mulheres permanecem por muito mais tempo do que os homens trabalhando com equipes de base, enquanto os homens, com menos tempo de atuação no mercado esportivo, já ocupam cargo de técnicos de equipes adultas e de seleções de voleibol de seus estados; (b) a realização de cursos de aperfeiçoamento pelas técnicas não foi suficiente para a sua inserção como treinadoras de equipes adultas e profissionais; no entanto, para os homens, a falta desses cursos não impediu que atuassem como técnicos destas mesmas equipes; (c) a maioria das mulheres gestoras não tem filhos, enquanto os homens prosseguem em suas carreiras sem ter na paternidade um empecilho.

A baixa representatividade das mulheres brasileiras no comando de equipes de voleibol indicia que elas se deparam com o fenômeno

\footnotetext{
${ }^{7} \mathrm{O}$ estudo realizado por Coelho (2010) afirma que a desvantagem por gênero é menos severa à medida que a posição na empresa requer mais altos níveis de qualificação. Para esses cargos, homens e mulheres são tratados de forma igualitária.
} 
do "teto de vidro", apresentado por Pfister e Radtke (2007), Botelho et al. (2010) e por Coelho (2010). As razões identificadas nos discursos das técnicas(as) para justificar a baixa participação das mulheres corroboram os argumentos encontrados nos estudos de Becker (1957), Arrow (1972) e Lazear e Rosen (1990) sobre a discriminação relacionada ao gênero e a força da tradição nos espaços de trabalho.

\subsection{DISCRIMINAÇÃO RELACIONADA A GÊNERO}

Segundo Moscovici (1978), os preconceitos jamais se manifestam isolados, eles assentam num fundo de sistemas, de raciocínio, de linguagens, no tocante à natureza biológica e social do homem e suas relações com o mundo. Esses sistemas estão constantemente interligados, transmitidos entre gerações e classes, e os que são objeto desses preconceitos veem-se mais ou menos coagidos a entrar no molde preparado e a adotar uma atitude conformista.

Quanto à baixa representação de mulheres no comando de equipes de voleibol de alto rendimento, é consenso dos entrevistados que a sociedade é preconceituosa neste aspecto. A discriminação pelo sexo, ancorada em fatores construídos culturalmente, impede ou dificulta que algumas mulheres assumam esse cargo.

A discriminação descrita no modelo do empregadordiscriminador estudado por Becker (1957) se manifesta no dia-a-dia da mulher que não tem acesso à posição de técnica e se pode verificar na fala de Ligia, "[...] basicamente a exclusão da mulher nesses cargos é cultural. Porque não é só dentro do esporte, mas a mulher durante muito tempo foi excluída".

Adiscriminação-estatística, prevista no modelo de Arrow (1972) também foi encontrada nas falas dos técnicos, que reforçam a imagem do "teto de vidro". A suposição de que a mulher é incapaz, ou de que sua produtividade é menor que a dos homens reduz a sua possibilidade de entrada no mercado. Os técnicos salientam a incapacidade das mulheres de comandarem equipes de alto nível, como podemos testemunhar na fala de Juca: 
Primeiro que elas ... a maioria delas se acha incapaz de dominar um grupo de meninos, por exemplo. E segundo é [pausa]. Porque elas é... são mais voltadas para a área de fitness e de dança. Elas acabam não se envolvendo muito com a parte do desporto. É um fator cultural (Juca).

No fragmento deste discurso, identificamos o que Giddens (2002) denominou de estilo de vida, em relação aos indivíduos. Com base no discurso dos técnicos, infere-se que os padrões gerais de estilo de vida das mulheres são influenciados por pressões de grupo e pela previsibilidade de modelo masculino, que afastam as mulheres desse espaço. Pois o espaço da gestão é culturalmente marcado como masculino e incompatível com o estilo de vida feminino.

As técnicas demonstram conhecer o imaginário masculino, que as considera incapazes para trabalhar com equipes de voleibol de alto rendimento, segundo a narrativa de Angélica "[...] menos mulheres do que homens como técnicas, pois ainda existe discriminação em relação ao potencial da mulher em algumas profissões, e o voleibol é uma delas".

Na representação dos técnicos de voleibol as áreas de trabalho são demarcadas de acordo com o sexo. Eles reconhecem que existe preconceito por parte da sociedade, e em sua explicação aderem aos preceitos que a tradição incorpora. Para eles, as razões para a baixa participação das mulheres nos cargos de comando de equipes de voleibol são: a) as mulheres tendem a procurar atividades mais voltadas para o fitness e a dança do que para desportos de alto rendimento; b) as equipes mais qualificadas não respeitarão o comando de uma técnica, confirmando que os méritos de um bom comando estão ancorados na figura masculina, e admitindo que as mulheres devam permanecer atuando nas equipes de base, local propício ao ensino do esporte; c) a falta provoca ausência: a falta de uma técnica que sirva de modelo é negativa para as mulheres que desejam esse cargo; d) a falta de experiência das mulheres no comando de equipes as impede de chegar no comando de equipes de categorias superiores de voleibol de rendimento. 
A leitura da síntese acima ilustra a rejeição do mundo do voleibol de rendimento por mulheres, na função de técnicas, mas não favorece a compreensão do fenômeno. Este impasse interpretativo nos leva a concordar com Moscovici (1978, p. 59), quando afirma que "De hábito, carecemos necessariamente de informações, de palavras, de noções, para compreender ou descrever os fenômenos que aparecem em certos setores do nosso meio ambiente".

Entende-se também que a mudança desse quadro só é possível com participação de mulheres reflexivas, dispostas a lutar por igualdade de oportunidades, comprometidas com a tarefa de criar mudanças positivas dentro das organizações, e assim disputar os cargos de comando. A disposição de mudar está presente nas falas das técnicas mais novas na profissão. Para elas, mudar fatores culturais e sociais, que ditam tarefas, posturas e posições que cabem a cada sexo é percebido como um objetivo a ser superado, rompendo com as práticas cristalizadas do passado. É delas que se ouvem depoimentos como o de Mara: "Ah! eu quero ser técnica de equipe adulta". Em contrapartida, as mulheres mais experientes com mais tempo na função, revelam uma atitude conformista, no sentido de que aceita como naturais as condições de ascensão na carreira.

Eu imagino que um dia seria legal algum trabalho, mas não na parte técnica propriamente, como técnica, como assistente, mas dentro do grupo de trabalho, né? [...] tomar conta da parte de do fundamento de "toque"? Eu adoraria! Mas é um trabalho de uma forma, mais paralelo ali. Ou de estatística, ou relacionado a isso. Mas almejar uma equipe para ser técnica, assistente, não! Muita coisa. [risos]. Eu gosto de ensinar. Não de tomar! [risos]. Ali você tem que conseguir.... controlar tudo, né? Vaidades, é!? Ser humano, não é fácil não! (Sônia).

A diferença de atitude face ao desafio foi identificada como uma das principais razões para as mulheres não ocuparem o cargo de técnicas de equipes superiores de voleibol. Elas ainda abrem mão da ascensão profissional em prol da maternidade, aceitam e reforçam a divisão dos papéis sociais. Para elas, a fase da maternidade deve 
ser de plena dedicação, muito mais do que se espera dos pais. Essa percepção é retratada no depoimento de Angélica:

Há uma fase da vida da mulher, quando resolvemos ser mãe, que realmente se torna impossível ser técnica de uma equipe de alto rendimento, pela falta de tempo. Mas acredito muito que a mulher é capaz, sim, de assumir uma equipe adulta, se for acompanhada de um bom grupo de trabalho, pois há fatores que a tornam inferior aos homens, como força, ter uma boa estrutura em sua casa para que não haja desgaste, a família apoiar e entender sua profissão, pois é normal para muitos o homem estar ausente, mas há uma cobrança muito grande quando é a mulher que fica ausente do lar. Existe obstáculo, sim. A própria questão da maternidade é um fator.

Este depoimento sintetiza um sentimento de impotência, falta de prontidão, aceitação do quadro assimétrico de distribuição do trabalho, configurando e reafirmando o poder e a força da metáfora do teto de vidro.

\subsection{A FORÇA DA TRADIÇÃO NOS ESPAÇOS DE TRABALHO}

As narrativas dos técnicos(as) revelam modelos sociais construídos culturalmente sobre as atitudes das mulheres no contexto esportivo. Elas atribuem valor-verdade ao poder controlador das representações, como coloca Moscovici, (2007, p.36) "[...] as representações são prescritivas, isto é, elas se impõem sobre nós com uma força irresistível. Essa força é uma combinação de uma estrutura que está presente antes mesmo que nós comecemos a pensar e de uma tradição que decreta o que deve ser pensado".

As falas de algumas entrevistadas reforçam a crença de que a baixa presença das mulheres nas equipes adultas de voleibol devese à postura de defesa com que elas próprias se colocam nesse espaço. Desistir da carreira de técnica alegando motivos pessoais significa uma derrota na batalha pela busca de igualdade de espaço no esporte de rendimento, segundo Miriam: "[...] não posso colocar total fator de culpa nesse machismo, pois, infelizmente, muitas 
mulheres que tentaram desistiram e não continuaram a batalhar, por diversos motivos pessoais, não estou aqui para julgar, mas não continuaram para mudar essa história".

Para a técnica Sonia as mulheres "[...] querem permanecer na educação, na formação inicial das atletas". Já a técnica Angélica justifica a baixa participação de mulheres nos cargos de técnicas de equipes adultas a partir das características femininas naturalmente dadas, e afinadas com o trabalho com crianças, como: "[...] dóceis, sensíveis, dedicadas, compreensivas, organizadas e assim com mais afinidade do que os homens para trabalhar com crianças".

Em síntese, podemos afirmar, com Goellner (2008, p.5), que às diferenças biológicas e os papéis construídos para o feminino são tomadas para "[...] justificar e atribuir funções sociais e determinar papéis a serem desempenhados por um ou outro sexo". Precisamos desconstruir a representação naturalizada de que homens e mulheres constroem-se masculinos e femininos pelas diferenças corporais e características cunhadas na feminilidade e na masculinidade, pois:

Não é o corpo "em si" que define a modalidade esportiva mais adequada para uma mulher nem mesmo se ela tem ou não capacidade para dirigir uma federação esportiva ou para treinar uma equipe de alto rendimento. É a discursividade construída sobre a funcionalidade do corpo e sua correlata associação aos processos de socialização que provoca e constrói tais demarcações (GOELLNER, 2007, p.189).

Cabe às mulheres reflexivas, que estão em condições de atuar como técnicas, de decidir se querem ou não entrar neste mercado. Mas a disposição para a luta não garante que o quadro se irá reverter em curto espaço de tempo. Urge criar outra cultura, que neutralize a força do teto de vidro.

\section{Considerações finals}

As mulheres têm pouca representação no comando de equipes de voleibol de alto rendimento, mesmo apresentando competência 
técnica, experiência e autonomia semelhantes aos homens. Elas permanecem trabalhando em sua maioria com equipes de voleibol das categorias de base. As barreiras que travam a inserção das mulheres no cargo de comando remetem para o fenômeno denominado de "teto de vidro", pois embora invisíveis tais barreiras controlam o acesso delas ao cargo de técnica. Como as mulheres historicamente não se inseriram nestes cargos, a própria cultura organizacional do esporte brasileiro, de forma subliminar, põe sob suspeita a atuação das técnicas, sua capacidade de atuar sob pressão e seu poder de decisão no dia a dia do esporte de alto rendimento. A docilidade, a sensibilidade e a compreensão presentes nas representações próprias que identificam o feminino sobressaem como razões para elas atuarem nas categorias de base. A força da tradição se faz presente na opção das mulheres pelo cuidado com os filhos, com a família e com a casa, que as "impede" de ocupar o cargo de técnica, pois este exige tempo integral, viagens e permanecer fora de casa por longos períodos, não se encaixando no modelo cultural de trabalho feminino. O desejo de combinar todas estas funções encaminha as técnicas para atuarem na formação esportiva de base. Embora esses cuidados afetem ambos os sexos, recaem mais fortemente sobre as mulheres e ampliam a desvantagem delas no mercado de trabalho esportivo de alto rendimento em comparação com os homens.

Como a inserção, permanência e ascensão na carreira de técnicas(as) de voleibol ocorrem obrigatoriamente a partir de um convite, esse perfil ideal projeta a figura e consequentemente a escolha dos homens para o cargo, mais do que as mulheres. Por decorrer dos interesses dos dirigentes de clubes, o convite funciona como um filtro nesse mercado, desconsiderando as mulheres. $\mathrm{O}$ modelo enraizado no esporte de rendimento brasileiro concebe a atuação da mulher na formação esportiva e o homem na performance, dividindo com referencia no sexo a atuação dos(as) técnicos(as) e mantendo a convicção de que os cargos de treinadores de equipes profissionais pertencem preferencialmente aos homens. 
Gender representations in brazilian volleyball: the "glass ceiling" metaphor.

Abstract: The objective of this article is to investigate the opportunities and the barriers encountered by coaches who wish to build a career working for professional Volleyball teams. We interviewed four male coaches and five female coaches and analyzed their discourse through content analysis. The results show male coaches looking to engage in this profession must display characteristics of autonomy, experience with the sport and technical knowledge. As for women who are seeking opportunities to coach professional Volleyball, displaying those same characteristics does not guarantee she will receive opportunities to coach, as if the qualifications to coach professional volleyball vary according to gender, confirming the metaphor of "Glass ceiling".

Keywords: Volleyball. Gender identify. Career mobility

Representaciones de género en el voleibol brasileño: imagen del techo de vidrio

Resumen: El objetivo de este artículo fue la investigación de las oportunidades y barreras que técnicos(as) de voleibol de alto rendimiento de equipos profesionales encuentran para la construcción de su carrera. Se entrevistó a cuatro técnicos y cinco técnicas y sus discursos que fueron analizados a través del Análisis de Contenido. Los resultados muestran que para que los técnicos puedan ingresar en la carrera profesional es fundamental la demostración de autonomía, experiencia y también el conocimiento técnico. Para las mujeres, autonomía, experiencia obtenida en las cuadras y conocimiento técnico no bastan para que sean llamadas a conducir equipos profesionales, lo que confirma la metáfora del "techo de vidrio".

Palabras clave: Voleibol. Identidad de Género. Movilidad laboral. 


\section{REFERÊNCIAS}

ARROW, K. Models of job discrimination. In: PASCAL, A. H. (ed.) Racial discrimination in economic life. Lexington: Heath, 1972. p. 83-102.

BARDIN, L. Análise de conteúdo. Lisboa: Edições 70, 2008.

BECKER, G. The economics of discrimination. Chicago: University of Chicago, 1957.

BOTELHO, L. L. R.; SCHONS, C.; VIEIRA, B.; CUNHA, C. J. C. A. Um olhar através do teto de vidro: relatos das mulheres empreendedoras de empresas baseadas no conhecimento sobre os primeiros anos de seus negócios. Disponível em: <http:/ /www.clee2008.ufsc.br/35.pdf>. Acesso em: 21 fev. 2010.

COELHO, D. Ascensão profissional de homens e mulheres nas grandes empresas brasileiras. In: DE NEGRI, J. A., DE NEGRI, F.: COELHO, D. (Ed.). Tecnologia, exportação e emprego Brasília, DF: Instituto Econômico de Pesquisa Aplicada, 2006. Cap. 6, p. 143-159.

COMITÊ OLÍMPICO INTERNACIONAL. Disponível em: <http://www.olympic.org/>. Acesso em: 10 out. 2009.

CONFEDERAÇÃO BRASILEIRA DE VOLEIBOL. Disponível em: <http:// www.volei.org.br>. Acesso em: 15 mar. 2009.

FEDERAÇÃO DE VOLEIBOL DO ESTADO DO RIO DE JANEIRO. Disponível em: <http://www.voleirio.com.br>. Acesso em: 10 ago. 2007.

FEDERAÇÃO PAULISTA DE VOLEIBOL. Disponível em: <http://www.fpv.com.br> Acesso em: 10 jul. 2008.

GIDDENS, A. Modernidade e identidade. Rio de Janeiro: Jorge Zahar, 2002.

GOELLNER, S. V. As mulheres fortes são aquelas que fazem uma raça forte: esporte, eugenia e nacionalismo no Brasil no início do século XX. Revista de História do Esporte, Rio de Janeiro, v. 1, n. 1, jun., p. 1-28, 2008. Disponível em <http://www.sport.ifcs.ufrj.br/recorde/pdf/recordeV1N1_2008_15.pdf> . Acesso em 31 jul. 2010.

Feminismos, mulheres e esportes: questões epistemológicas sobre o fazer historiográfico. Movimento, Porto Alegre, v.13, n. 02, p.171-196, maio/ago. 2007.

Mulheres e esporte em perspectiva. Disponível em: $<$ http:// cbtmweb.winexam.com.br/scripts/arquivos/esporte_mulher.pdf>.Acesso em: 20 jul. 2009. 
GOMES, E. M. P. A participação das mulheres na gestão do esporte brasileiro: desafios e perspectivas. Rio de Janeiro: Quartet: FAPERJ, 2008.

LAZEAR, E. P.; ROSEN, S. Male-female wage differentials in job ladders. In: Journal of Labor Economics, Chicago, v. 8, n. 1, p.s106-123, jan. 1990.

LOCKS G. G.; MOURÃO L.; OLIVEIRA A. P.; SANTOS R. F. Treinamento de equipes mirins e infantis femininas: a concepção dos treinadores de voleibol do estado do Rio de Janeiro. <http://www.revistas.ufg.br/index.php/fef/article/ view/5571>. Acesso em: 23 jul. 2009.

MOSCOVICI, S. A representação social da psicanálise. Rio de Janeiro: Zahar, 1978.

Preconceito e representações sociais. In: OLIVEIRA, A.M.; JODELET, D. (Orgs). Representações sociais: interdisciplinaridade e diversidade de paradigmas. Brasília: Thesaurus, 2009.

Vozes, 2007.

Representações sociais: investigações em psicologia social. Petrópolis:

MOURÃO, L. A representação social da mulher brasileira na atividade físico-desportiva: da segregação à democratização. Tese (Doutorado em Educação Física). Universidade Gama Filho, Rio de Janeiro, 1998.

MOURÃO, L.. Exclusão e inserção da mulher brasileira em atividades físicas e esportivas. In: SIMÕES, A. C. (Org). Mulher e esporte: mitos e verdades. São Paulo: Manole, 2003.

PFISTER, G. ; RADTKE, S. Mulheres tomando a liderança ou mulheres tomando a liderança nas organizações esportivas alemãs. Movimento, Porto Alegre, v. 13, n. 2, p. 91-129, maio/ago. 2007.

RADTKE, S. III Interview study: Biographies of women in honorary executive positions in German sport. In: DOLL-TEPPER, G.; PFISTER, G.; RADTKE, S.; (Orgs). Progress towards Leadership: Biographies and career paths of male and female leaders in German sports organizations. Berlin: Auflage Sportverlag Straub, 2006. p. 71140.

ROMARIZ, S. B. Práticas e representações de gênero no voleibol brasileiro. Tese (Doutorado em Educação Física). - Universidade Gama Filho, Rio de Janeiro, 2010.

SOARES, T. A. Mulheres em ciência e tecnologia: ascensão limitada. Química Nova: São Paulo, v. 24 n. 2, p. 281- 285, mar./apr. 2001. Disponível em: <http:// quimicanova.sbq.org.br/qn/qnol/2001/vol24n2/19.pdf>. Acesso em: 5 jan. 2010. 
SOUZA DE OLIVEIRA, G. A. Representações sociais de mulheres técnicas sobre o comando de equipes esportivas de alto nível. Dissertação (Mestrado em Educação Física) Universidade Gama Filho, Rio de Janeiro, 2002.

THOMAS, J. R.; NELSON J. K. Métodos de pesquisa em atividades físicas. Porto Alegre: Artmed, 2007.

BRASIL. MINISTÉRIO DA FAZENDA. Diário Oficial da União, Brasília, DF, $31 \mathrm{dez}$. de 1979. Seção 1, Pt.1 : Atos do poder executivo, p. 202-220.

Endereço para correspondência:

Sandra Bellas de Romariz

Rua Dr. Mário Viana 456 casa 102 B- Bairro: Santa Rosa- Niterói/ RJ.

CEP: 24 241-002

tel: (21) 2710-4281

Recebido em: 11-09-2012

Aprovado em: 31-10-2012

Movimento, Porto Alegre, v. 18, n. 04, p. 219-237, out/dez de 2012. 
